\title{
Bridging gaps in access to ophthalmology mentorship with the virtual Canadian Ophthalmology Mentorship Program
}

(c) The Author(s), under exclusive licence to The Royal College of Ophthalmologists 2021

Eye (2022) 36:1848-1849; https://doi.org/10.1038/s41433-021-01899-y

\section{TO THE EDITOR:}

We congratulate Dr. Scantling-Birch and colleagues for their insightful editorial on the landscape of contemporary ophthalmology education [1]. As a discipline with already limited exposure in medical school teaching curricula, ophthalmology faced additional challenges during the COVID-19 pandemic following the loss of in-person clinical experiences [2]. At times, crisis begets opportunity, as is evident from the emergence of virtual learning communities which have advanced knowledge and facilitated networking during the COVID-19 pandemic. Two examples include the Canadian Ophthalmology Student Interest Group (COSIG) founded by medical students and the recently piloted Canadian Ophthalmology Mentorship Program (COMP), which represents a collaboration between COSIG and the Council of Canadian Ophthalmology Residents [3].

COMP adopts a two-pronged approach to mentorship: first, medical students are paired with resident physicians across the country via COMP Mentorship Groups; second, medical students are invited to monthly discussions featuring ophthalmologists and resident physicians via COMP Speaker Series (Fig. 1). Launched in September 2021, this mentoring initiative has been met with overwhelming interest from both mentors and mentees in the Canadian ophthalmology community. The first round of COMP Mentorship Groups paired 135 medical students with 45 residents from across Canada, all of whom connected virtually. The ongoing COMP Speaker Series covers topics from equity and wellness in ophthalmology to a cross-country resident panel series, with a range of 41-98 attendees per event to date.

COMP was borne from the observation that gaps in mentorship for medical students interested in ophthalmology [4] were amplified by COVID-19. Mentorship is an essential component to bolstering career satisfaction, and establishing relationships early sets the stage for maintaining them through one's career [5]. Indeed, a robust mentorship program is pivotal in efforts to support inclusion, diversity, equity, and access. As demonstrated by Dr. Scantling-Birch and colleagues, the ophthalmology community benefits from embracing technology as a tool to engage medical students in the discipline. Pandemic-era medical education need not be defined by the decline of traditional learning strategies, but instead viewed as an opportunity to embrace innovative opportunities for learning, mentorship, and collaboration. We look forward to the many visionary initiatives taking form in undergraduate medical education of ophthalmology during COVID-19.

\section{Canadian Ophthalmology Mentorship Program (COMP)}

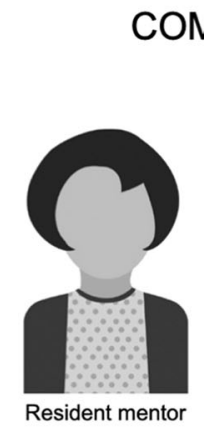

COMP Mentorship Groups

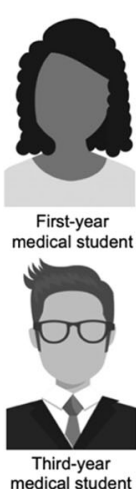

medical studen

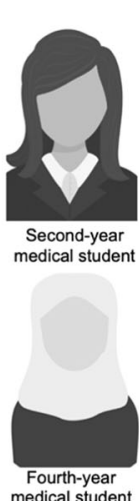

Mentorship groups composed of 2-4 medical students (mentees) paired with a Canadian ophthalmology resident (mentor)

COMP Speaker Series

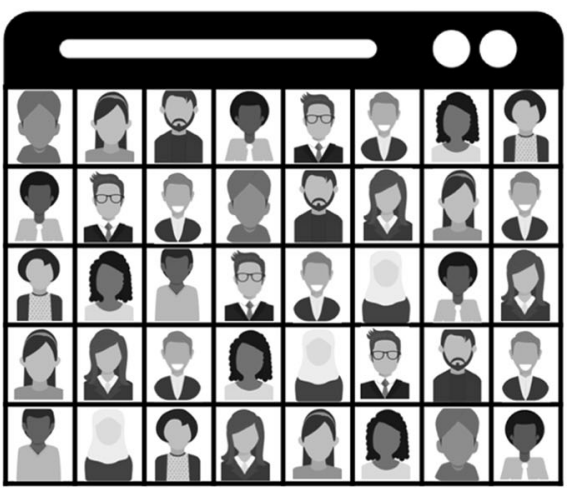

Monthly online discussions featuring faculty speakers (mentors) and medical students (mentees)

Fig. 1 COMP is comprised of a structured approach to mentorship groups and speaker series. Mentorship groups include 2-4 medical students (mentees) with one resident physician (mentor). Speaker series comprise monthly discussions with staff ophthalmologists and resident physicians. 
Stuti M. Tanya $\mathbb{D}^{1 凶}$, Anne X. Nguyen (iD) ${ }^{2}$, Daiana Roxana Pur ${ }^{3}$, Michael Nguyen ${ }^{4}$, Femida Kherani ${ }^{5}$, Fiona Costello ${ }^{5}$ and Radha Kohly ${ }^{4}$

${ }^{1}$ Faculty of Medicine, Memorial University of Newfoundland, St. John's, NL, Canada. ${ }^{2}$ Faculty of Medicine, McGill University, Montréal,

QC, Canada. ${ }^{3}$ Schulich School of Medicine and Dentistry, Western University, London, ON, Canada. ${ }^{4}$ Department of Ophthalmology \& Vision Sciences, University of Toronto, Toronto, ON, Canada.

${ }^{5}$ Department of Surgery, Section of Ophthalmology, University of Calgary, Calgary, AB, Canada. ${ }^{\bowtie}$ email: stanya@mun.ca

\section{REFERENCES}

1. Scantling-Birch $Y$, Naveed $H$, Tollemache N, Gounder P, Rajak S. Is undergraduate ophthalmology teaching in the United Kingdom still fit for purpose? [published online ahead of print, 2021 Aug 30]. Eye (Lond). 2021;10.1038/s41433-021-01756y. https://doi.org/10.1038/s41433-021-01756-y

2. Nguyen AX, Clark I, Damji KF, Hamel P, Bélair ML, Goodyear É, et al. New virtual CaRMS: perspectives from residency programs. Can J Ophthalmol. 2021;56:273-6. https://doi.org/10.1016/j.jcjo.2020.12.007. Epub 2021 Jan 6. PMID: 33421378

3. Canadian Ophthalmology Student Interest Group. Mentorship | COSIG-GECIO. https://www.cosig-gecio.com/mentorship. 2021. Accessed October 9, 2021.

4. Nassrallah G, Arora S, Kulkarni S, Hutnik CML. Perspective on a formal mentorship program in ophthalmology residency. Can J Ophthalmol. 2017;52:321-2. https:// doi.org/10.1016/j.jcjo.2017.03.005

5. Kletke SN, Zhang A, Kohly RP. A national survey of Canadian women in ophthalmology: on role models, mentorship, and communities of practice. Can J Ophthalmol. 2021;56: 203-5. https://doi.org/10.1016/j.jcjo.2020.10.004

\section{ACKNOWLEDGEMENTS}

We would like to acknowledge the Canadian Ophthalmology Student Interest Group for their support of the Canadian Ophthalmology Mentorship Program.

\section{AUTHOR CONTRIBUTIONS}

ST: Conceptualization, Writing-Original Draft, Writing-Review \& Editing, Visualization, Project Administration. AN: Conceptualization, Writing-Original Draft, Writing-Review \& Editing, Visualization. DP: Conceptualization, Writing-Review \& Editing. MN: Writing-Review \& Editing, Supervision, Project Administration. FK: Writing-Review \& Editing, Supervision. FC: Writing—Review \& Editing, Supervision. RK: Writing—Review \& Editing, Supervision.

\section{COMPETING INTERESTS}

The authors declare no competing interests.

\section{ADDITIONAL INFORMATION}

Correspondence and requests for materials should be addressed to Stuti M. Tanya.

Reprints and permission information is available at http://www.nature.com/ reprints

Publisher's note Springer Nature remains neutral with regard to jurisdictional claims in published maps and institutional affiliations. 